\title{
Ovipositional Behaviour of Two Fruit Flies, Ceratitis capitata and Anastrepha fraterculus, in Seven Fruit Hosts in the Laboratory
}

\author{
Ester Marques de Sousa', Léo Rodrigo Ferreira Louzeiro', \\ Miguel Francisco de Souza-Filho ${ }^{1}$ and Adalton Raga ${ }^{1^{*}}$ \\ ${ }^{1}$ Instituto Biológico, Secretaria da Agricultura e Abastecimento do Estado de São Paulo. Alameda dos \\ Vidoeiros 1097, 13101-680, Campinas, SP, Brazil.
}

Authors' contributions

This work was performed in collaboration among all authors. Author AR designed the study and wrote the first draft of the manuscript. Authors EMS and LRFL contributed to the maintenance of fruit-fly colonies and the development of the experiments. Author MFSF help to evaluate the fly oviposition and take pictures. All authors read and approved the final manuscript.

Article Information

DOI: 10.9734/ARRB/2020/v35i1130303 Editor(s):

(1) Dr. Bechan Sharma, University of Allahabad, India.

Reviewers:

(1) Gaurang Chhangani, Maharana Pratap University of Agriculture and Technology (MPUAT), India.

(2) Mohammed Ezziyyani, Université Abdelmalek Essaâdi, Morocco. Complete Peer review History: http://www.sdiarticle4.com/review-history/62598

Original Research Article

Received 26 August 2020

Accepted 02 November 2020

Published 23 November 2020

\begin{abstract}
Anastrepha fraterculus (Wiedemann) and Ceratitis capitata (Wiedemann) are the most commonly found fruit fly species in fruit crops in Brazil. Both polyphagous species show similar host ranges, but specific knowledge regarding the ovipositional preference of either species is scarce. The present study aims to evaluate, in the laboratory, ovipositional behaviours in seven fruit host submitted to infestation by $A$. fraterculus and C. capitata. Except for C. capitata in Tahiti acid lime, the number of punctures containing eggs exceeded the number of punctures without eggs. The highest values for eggs per puncture were obtained in Fuyu persimmon, for which averages of 4.06 and 50.09 eggs per puncture were deposited by $A$. fraterculus and $C$. capitata, respectively. For $A$. fraterculus, the infestation ranking, based on the number of eggs per puncture from high to low, was Fuyu persimmon $>$ papaya $>$ Tahiti acid lime $>$ carambola $>$ coffee $>$ guava $>$ sweet orange. For $C$. capitata, the infestation ranking was Fuyu persimmon $>$ carambola $>$ papaya $>$ guava $>$ sweet orange $>$ coffee $>$ Tahiti acid lime. All punctures made to carambola and papaya contained eggs.
\end{abstract}


Sweet orange exhibited the maximum number of punctures of $A$. fraterculus without egg deposition. The first day of medfly oviposition in Fuyu persimmon resulted in approximately three-fold more eggs per puncture than the second, third, and fourth days.

Keywords: Tephritidae; egg masses; Tahiti lime, carambola; Fuyu persimmon.

\section{INTRODUCTION}

Female insects choose where to lay eggs on any substrate [1] because this process is the most important event in the lives of female insects [2]. Therefore, host preference is defined as the hierarchical ordering of host plants by ovipositing females [3]. Polyphagous Tephritidae species have received the most attention in research examining host selection behaviours, but the data are rarely robust enough to define the host status [4]. A number of behavioural traits are influenced by egg load, including the persistence with which females forage for oviposition sites, the probability that a host is accepted, and even the size of a female's clutch [5], once the skin puncture resistance can serve as an important deterrent to oviposition [6].We would expect plasticity in ovipositional behaviours associated with the environmental context [1] and a variety of factors, including fly density, age, nutrition, egg load, fruit size and ripeness, the existence of previous punctures, and even weather are expected to guide a fly's egg laying decisions [7]. Moreover, flies also are more likely to oviposit in a host fruit in the presence of a conspecific ovipositing fruit fly than in the absence of other flies [8].

In general, females of the frugivorous Tephritidae deposit oviposition-deterring pheromones on the fruit surface immediately after oviposition, to reduce the probability of intraspecific competition between maggot for the food supply [9]. The choice among available hosts and the oviposition rate is also likely to be influenced by the supposed host quality for larval development $[10,11]$. The Mediterranean fruit fly (medfly), Ceratitis capitata (Wiedemann), marks its hosts (pheromone) and yet prone to multiple oviposition in those fruit hosts, despite the presence of naturally deposited host-marking pheromones [12].

Anastrepha fraterculus (Wiedemann) and the exotic C. capitata are the main primary fruit flies (Tephritidae) in Brazil [13] and have been recorded to oviposit in 116 and 94 hosts, respectively [14, 15]. However, data regarding fruit fly oviposition are rare in the literature, especially for $A$. fraterculus. This study was conducted to increase our knowledge of the ovipositional behaviour of both fruit flies, which will assist the management of pest populations in different hosts and provide basic information for pest risk analysis and plant health services.

The objective of this study was to evaluate the ovipositional behaviour in seven fruit hosts submitted to infestation by $A$. fraterculus and $C$. capitata: carambola (Averrhoa carambola L.), coffee (Coffea arabica L.), guava (Psidium guajava L.), papaya (Carica papaya L.), persimmon (Diospyros kaki L.), sweet orange (Citrus sinensis L. Osbeck), and Tahiti lime (Citrus latifolia Tanaka), under laboratory conditions.

\section{MATERIALS AND METHODS}

\subsection{Fruit Fly Colonies and the Location of the Experiment}

Adults of $A$. fraterculus and C. capitata were obtained from a culture maintained since 1993 by the Economic Entomology Laboratory, Instituto Biológico, in Campinas, SP, Brazil [16]. After emergence, flies were provided with water and a mixture (w/w) of sugar $(49.1 \%)$, brewer's yeast $(24.5 \%)$, yeast extract $(12.2 \%)$, wheat germ $(12.2 \%)$, and Sustagen ${ }^{\circledR}(2.0 \%)$.

\subsection{Infestation Bioassays}

\subsubsection{Test 1}

All tested fruits in the experiments were either ripe or full-ripe (Table 1), based on external visual fruit colour, and were washed thoroughly under running tap water before testing. Due to differences in fruit sizes among the fruit species, we establish the following numbers of fruits per infestation cage: carambola (10), coffee cv. 'Mundo Novo' (75), guava cv. 'Tailandesa' (8), papaya (3), persimmon cv. 'Fuyu' (4), sweet orange cv. 'Pera' (10), and acid lime cv. 'Tahiti' (20). An additional sample of the fruits without infestation was kept in the laboratory to check the possibility of pre-harvest oviposition. 
Table 1. The number of eggs per puncture $(n=100)$ for two fruit fly species (Tephritidae) in seven fruit hosts, under laboratory conditions

\begin{tabular}{llll}
\hline Fruit host & Ripe (R) or & \multicolumn{2}{c}{ Eggs per puncture (mean \pm SE) } \\
\cline { 2 - 4 } & Full ripe (FR) & Anastrepha fraterculus & Ceratitis capitata \\
\hline Carambola & $\mathrm{R}$ & $1.42 \pm 0.07 \mathrm{cB}$ & $31.03 \pm 2.15 \mathrm{bA}$ \\
Guava & $\mathrm{R}$ & $1.13 \pm 0.05 \mathrm{cB}$ & $13.26 \pm 2.15 \mathrm{cA}$ \\
Papaya & $\mathrm{R}$ & $2.69 \pm 0.13 \mathrm{bB}$ & $29.84 \pm 2.51 \mathrm{bA}$ \\
Coffee & $\mathrm{FR}$ & $1.16 \pm 0.05 \mathrm{cB}$ & $3.17 \pm 0.38 \mathrm{dA}$ \\
Sweet orange & $\mathrm{R}$ & $0.75 \pm 0.08 \mathrm{~dB}$ & $10.39 \pm 1.48 \mathrm{cA}$ \\
Fuyu persimmon & $\mathrm{FR}$ & $4.06 \pm 0.29 \mathrm{aB}$ & $50.09 \pm 3.68 \mathrm{aA}$ \\
Tahiti acid lime & $\mathrm{R}$ & $1.47 \pm 0.14 \mathrm{cA}$ & $0.10 \pm 0.05 \mathrm{eB}$ \\
\hline \multicolumn{2}{c}{ Original means within a column followed by the same letter and means within a row followed } \\
\multicolumn{2}{r}{ by the same upper case letter do not significantly differ by Tukey's test $(P \leq 0.05)$}
\end{tabular}

Each fruit species was randomly placed on the infestation cage floor $(50 \mathrm{~cm}$ length; $40 \mathrm{~cm}$ height; $40 \mathrm{~cm}$ width) and separately exposed to 200 mature females over 24 hours. The ages of the females ranged from $12-15$ days-old for $A$. fraterculus and 8-10 days-old for C. capitata. Water and the standard diet described above for adult flies were provided in each cage. The average humidity, temperature, and photophase in the laboratory were maintained at $56 \%-61 \%$, $19.2-23.8^{\circ} \mathrm{C}$, and $14 \mathrm{~h}$, respectively.

\subsubsection{Test 2}

In a second experiment, three full-ripe persimmons were daily exposed to medfly females (8-day-old) in an infestation cage for four days to measure whether egg-laying decreased over time. The fruit was exposed to 10 females per fruit in the same cage. The test was conducted using the conditions described for Test 1 , and the number of punctures $(n=50)$ was evaluated daily.

\subsection{Evaluation and Statistical Analysis}

During Test 1, 100 punctures for each infested fruit species and during Test 2, 50 punctures by C. capitata in 'Fuyu' persimmon were evaluated. Punctures were examined under a stereoscopic trinocular microscope (Carl Zeiss Stemi 2000-C), by counting the number of eggs per puncture. Images of the punctures and eggs were obtained using a digital camera (Canon Power Shot A650 IS) attached to the microscope.

The results were analysed using a two-way analysis of variance (ANOVA) to compare the number of eggs per puncture by both species of fruit flies in different fruit species (Test 1). A oneway ANOVA was used to analyse the puncture data in persimmon (Test 2). We transformed the data using the square root $(x+1)$, and ANOVAs were performed using Sisvar, version 5.7 [17], with significance set to $P<0.05$. Comparison between treatments was made using Tukey's test.

\section{RESULTS}

\subsection{Test 1}

The highest numbers of eggs per puncture were obtained in Fuyu persimmon, with averages of 4.06 and 50.09 eggs per puncture by $A$. fraterculus and C. capitata, respectively (Table 1). For $A$. fraterculus, sweet orange showed the minimum number of eggs per puncture (0.75); whereas, for medfly, Tahiti acid lime showed the minimum number of eggs per puncture $(0.10)$.

Carambola, guava, coffee, and Tahiti acid lime exhibited similar values for mean eggs per puncture by $A$. fraterculus (Table 1). Guava (13.26) and sweet orange (10.39) showed similar values for mean eggs per puncture by medfly. Coffee berries showed a sharp decrease in the number of $C$. capitata eggs per puncture compared with other fruits (3.17). Papaya was considered to be an intermediate host in terms of egg masses for both $A$. fraterculus (2.69) and $C$. capitata (29.84).

Except for in Tahiti acid lime, the other host fruits showed higher numbers of eggs per puncture by C. capitata than by $A$. fraterculus (Table 1 ). Only five punctures made by $C$. capitata in Tahiti acid lime contained eggs because the female avoided oviposition in the remaining punctures (Fig. 1). In contrast, only 12 punctures showed no egg deposition by $A$. fraterculus in Tahiti acid lime. Anastrepha fraterculus females exhibited intensive ovipositional stimuli after only a few minutes of exposure to Tahiti fruits in the laboratory cage, because the punctures exuded strong aromas due to essential oils. 


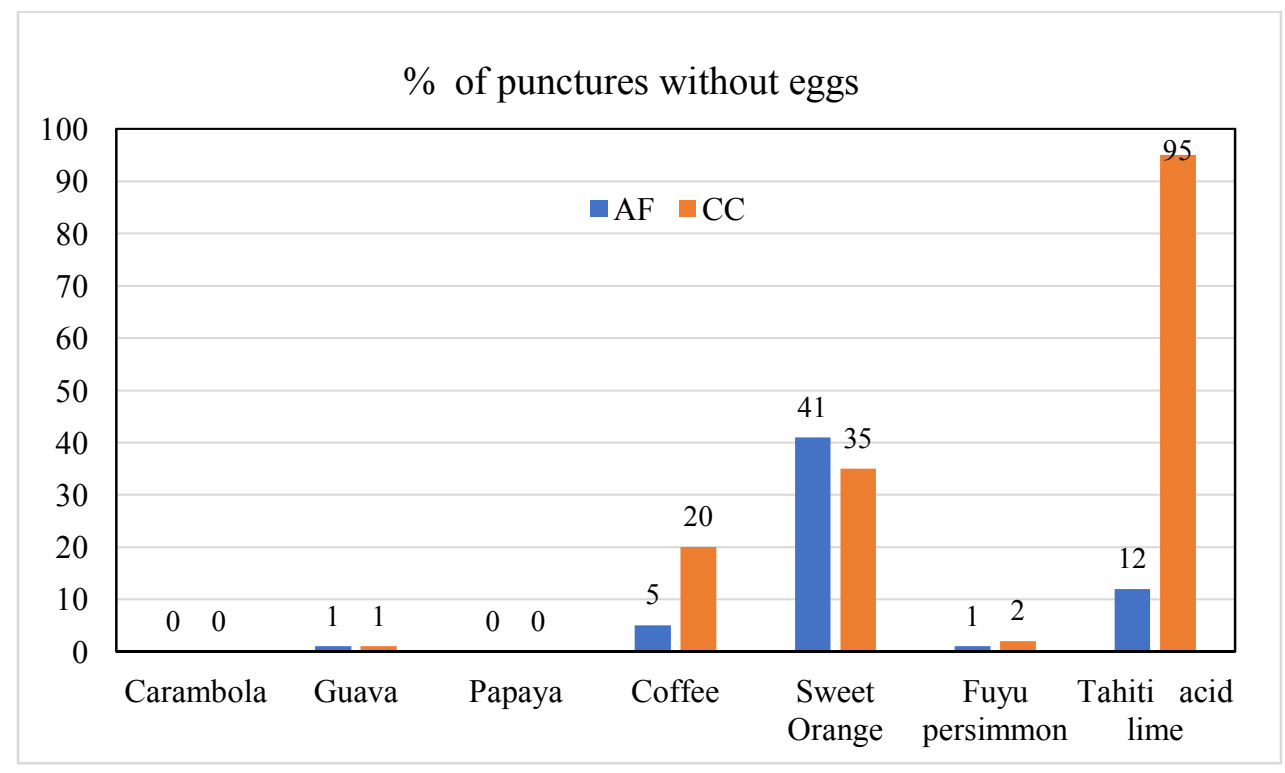

Fig. 1. Percentage of punctures without eggs by Anastrepha fraterculus (AF) and Ceratitis capitata (CC) in seven host fruits, under laboratory conditions
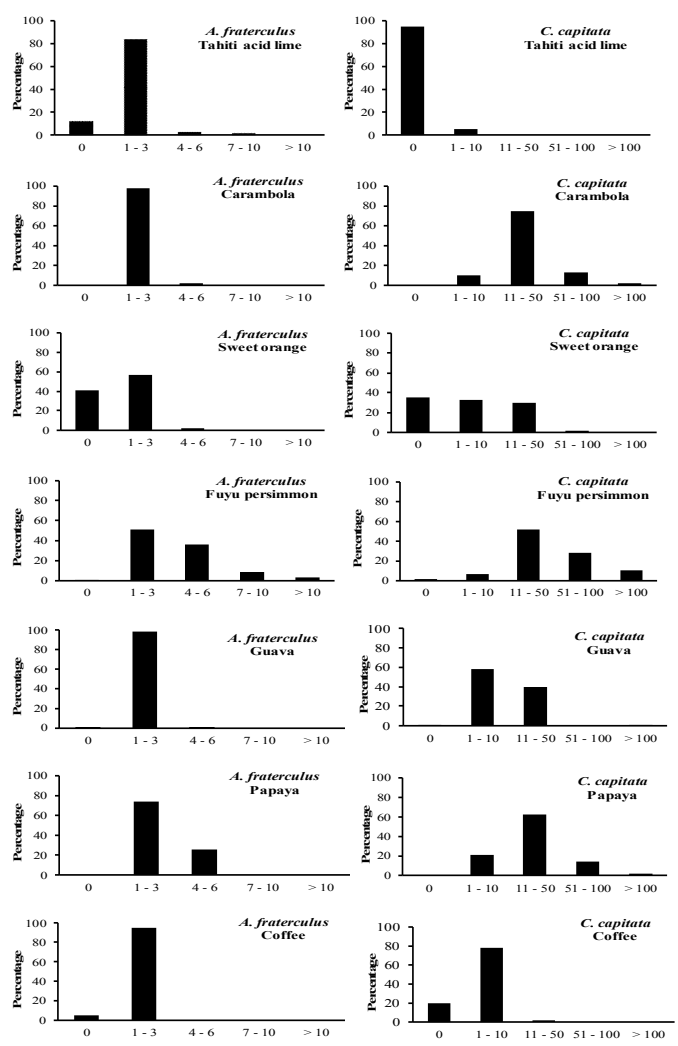

Fig. 2. Percentage distribution of classes for the number of Anastrepha fraterculus and Ceratitis capitata eggs per puncture in different fruit hosts, under laboratory conditions 
All punctures observed in carambola and papaya contained eggs. Sweet orange exhibited high rate of $A$. fraterculus punctures without oviposition (Fig. 1). The majority of punctures made by $A$. fraterculus in all the fruit hosts showed between 1 and 3 eggs. Most of the egg masses laid by $C$. capitata in carambola, Fuyu persimmon, and papaya exhibited between 11 and 50 eggs (Fig. 2). Fuyu persimmon contained the largest egg masses in a single puncture for both species: 21 eggs for $A$. fraterculus and 161 eggs for C. capitata. The majority of punctures made in coffee berries presented up to $3 \mathrm{~A}$. fraterculus eggs or $10 \mathrm{C}$. capitata eggs. The punctures and ovipositions on fruit hosts provided by both fruit flies are illustrated in the Fig. 3.

\subsection{Test 2}

Medflies laid eggs over a four-day period and in all punctures made in Fuyu persimmons exhibited at least two eggs. Significant difference in the numbers of eggs per puncture was observed for the first day of oviposition (mean 27.86 eggs) compared to that for remaining days, which were at similar levels (Fig. 4).

A maximum of $84,33,19$ and 22 eggs of $C$. capitata by puncture were obtained on the first, second, third and fourth day of exposure. The second, third and fourth days of oviposition showed average reductions of $63.4 \%, 59.6 \%$, and $66.1 \%$ in eggs per puncture, respectively compared to that for day 1 .

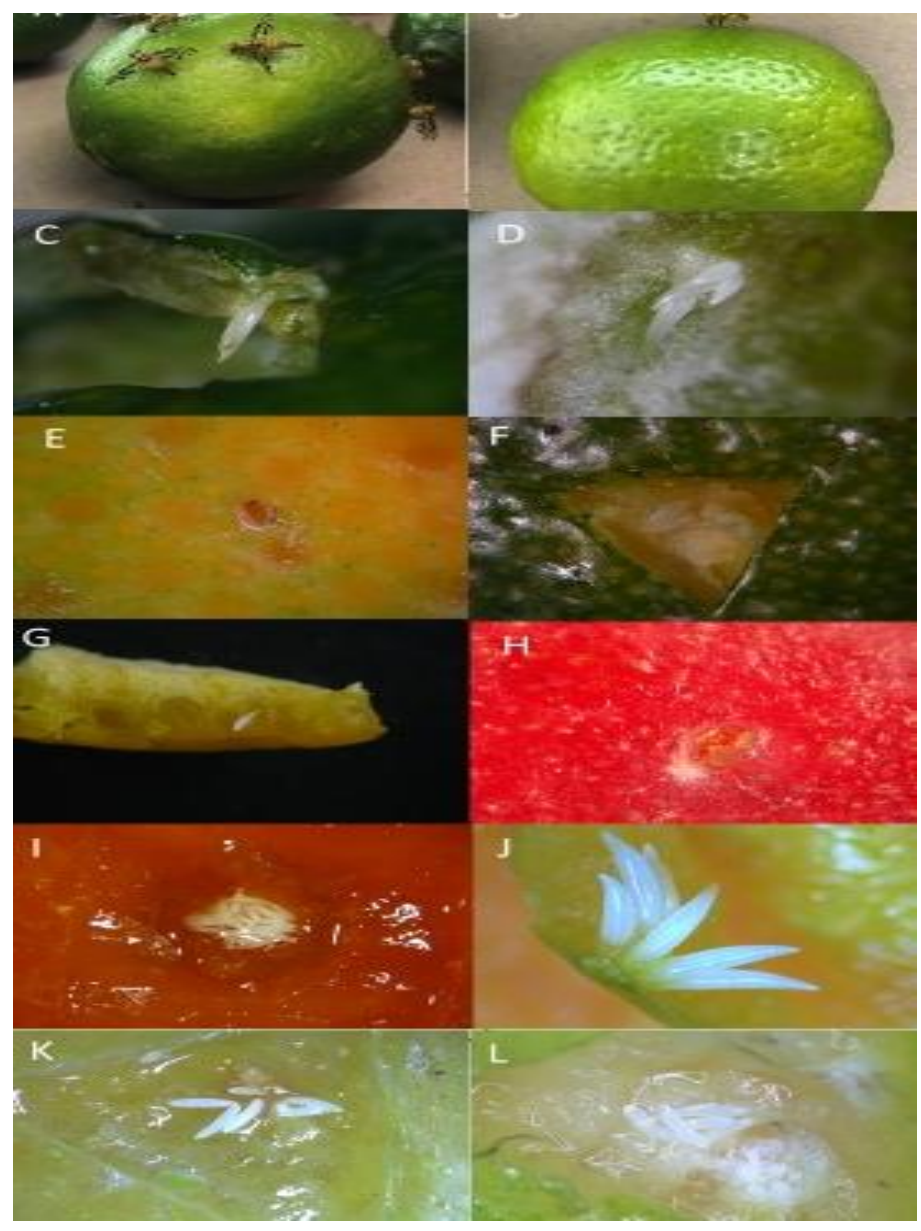

Fig. 3. Oviposition (A. B) and eggs (C, D) of $A$. fraterculus in Tahiti acid lime; puncture (E) and egg masses (F) of $C$. capitata in sweet orange; $A$. fraterculus egg in sweet orange (G); puncture in coffee cherry (H); C. capitata egg masses in Fuyu persimmon (I); $A$. fraterculus oviposition in papaya (J); C. capitata oviposition in carambola (K); C. capitata egg masses in guava (L) 


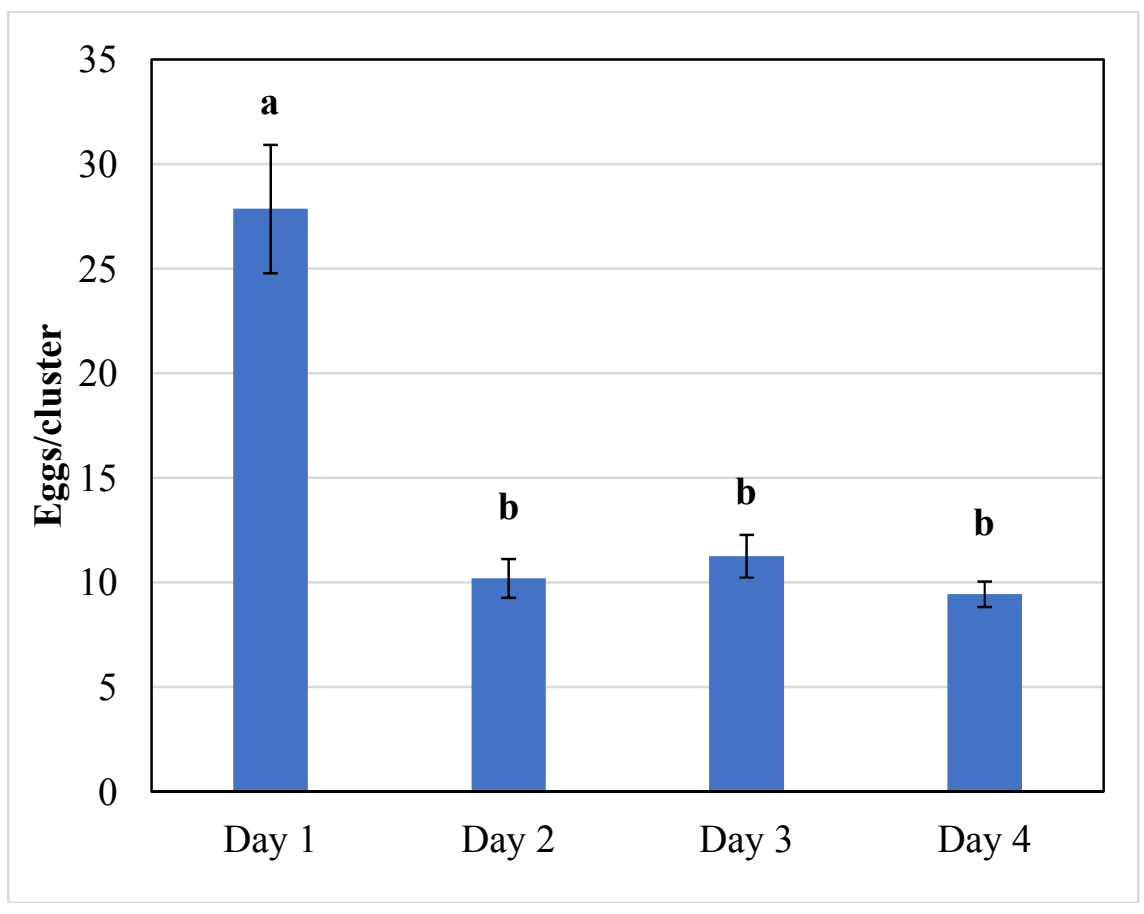

Fig. 4. Daily oviposition of Ceratitis capitata in Fuyu persimmon ( $n=50$ clusters), under laboratory conditions. Bars followed by the same letter indicate no significant difference at $P>$ 0.05 (Tukey's test)

\section{DISCUSSION}

Except for medfly oviposition in Tahiti acid lime, the number of ovipositing events exceeded the number of punctures without eggs for the two tested fly species. A similar result was reported by McDonald \& Mclnnis [18] for C. capitata in peach, apple, plum, and grape.

Depending on the larval host rearing, $C$. capitata can lay up to 690 eggs in total $[19,20,21]$ and $A$. fraterculus can lay up to 460 eggs throughout their lifespans [22].

Females of $A$. fraterculus and $C$. capitata differ substantially in clutch sizes. From all tested fruit hosts, $58 \%$ of oviposition events for $A$. fraterculus resulted in only one egg; whereas, this rate was $4.6 \%$ in C. capitata. Eighty-six percent of the punctures made by Bactrocera latifrons (Hendel) on pepper, Capsicum annum $\mathrm{L}$. contained one egg [23]. These results suggested that the ovipositional behaviours of tephritid flies are variable. Therefore, understanding the various ovipositional aspects associated with the behaviours of each fly species is necessary to understand the population dynamics and management of each individual species.
Similar differences in clutch sizes were observed between Anastrepha obliqua (Macquart), which generally oviposits one egg, and Anastrepha ludens (Loew), which typically lays up to 40 eggs [24]. Ceratitis capitata females lay one to ten eggs per clutch [25]. In contrast, according to our results, multiple oviposition events at the same puncture appeared to be unusual behaviour for A. fraterculus.

Although multiple oviposition events are not easily observed characteristics when examining the peels of our tested fruits, medflies may oviposit into a pre-existing puncture because this structure represents a positive stimulus for $C$. capitata egg-laying [12]. Sweet orange presented similar distributions $C$. capitata eggs among the classes of egg masses (Fig. 2). The reasons for high variability in the number of eggs per puncture may be due to the use of the same puncture by multiple females. This behaviour represents a substantial increase in phytosanitary risk for transportation and the commercial sale of medfly fruit hosts, even under lower infestation rates.

The egg loads of $A$. ludens and $A$. obliqua females that were housed with other females 
were significantly greater than the egg loads of isolated females [5]. Anastrepha ludens females not only produce eggs continuously to be able to quickly respond to egg-laying opportunities, but the eggs they produce are largely fertile [26].

Depending on the fruit host, the social facilitation of egg-laying behaviours among fruit flies $[8,27]$ may stimulate multiple ovipositing events by multiple $C$. capitata females in the same puncture, as noted for $C$. capitata in sweet granadilla Passiflora ligularis (Juss.) [28]. Even social facilitation behaviours are not a ubiquitous phenomenon among all fruit flies [7]. In our case, social facilitation behaviour likely stimulated the ovipositional behaviours of $A$. fraterculus in Fuyu persimmon, papaya, carambola, and Tahiti acid lime.

Although the system approach technique, which is used in areas that grow and export papayas, is based on harvesting fruits during maturation stages 1 and $2[29,30]$, females of $A$. fraterculus and $C$. capitata deposited higher numbers of eggs in the soft peels of ripe fruits, under laboratory conditions. Diaz et al. [31] obtained the largest numbers of $A$. fraterculus and $C$. capitata eggs in the fruits of mango and papaya, respectively. The authors attributed this behaviour to "pre-imaginal conditioning" because the insects used in the experiment were reared in the mentioned hosts. In the present study, similar behaviours may partially explain the rate of oviposition by $A$. fraterculus in papaya (2.69 eggs/puncture).

The oviposition of $A$. fraterculus and $C$. capitata in citrus fruits occurred in the oil cells of flavedo [32]. Spliter et al. [33] observed a secretion on the surface of lemon, Citrus limon L., cv. Eureka and Lisbon, after medfly oviposition, which sealed the puncture and closed the egg cavity. We detected similar symptoms in Tahiti acid lime but not in sweet orange, which shows that nearly all punctures remained open. A group of $A$. fraterculus females stimulated each other to increase ovipositing behaviours, likely influenced by the aromas of peel volatiles produced by Tahiti acid lime [34], which were emitted by earlier punctures. Socially facilitated behaviour was not detected in medflies on Tahiti acid lime, and even though the females landed on the fruit surface and created punctures, they avoided oviposition, exhibiting only five egg masses with a maximum of 3 eggs per clutch.

Many species of fruit may be infested under the pressure of hundreds of ovipositing fruit fly females in a confined setting; however, under field conditions fewer than 5 flies land on any single fruit [35] and either $A$. fraterculus and $C$. capitata detect conspecific and heterospecific infested fruits [36].

A significant influence of host plants was observed on the different developmental parameters of Zeugodacus cucurbitae (Coquillett) [37]. Our results suggested that the fruit host may change ovipositional behaviours, either increasing or decreasing the sizes of the egg masses. Urophora cardui (L.) females (Tephritidae) are able to measure bud quality and adapt clutch sizes accordingly [38]. Carambola was the second-most preferred fruit host in terms of egg masses when exposed to $C$. capitata (Table 1) and is commonly infested by medfly in the state of São Paulo [39].

Fuyu persimmon, a non-astringent persimmon, presented the highest levels of oviposition for both fruit fly species. Total and soluble tannins were shown to decrease throughout development in Fuyu persimmon [40], which is favourable for the larval development of $A$. fraterculus and C. capitata [41]. In contrast, coffee berries showed the lowest mean number of eggs for $A$. fraterculus per puncture, and very small egg masses of $C$. capitata eggs were observed. The ovipositional behaviours of both species in coffee are likely affected by the thin layers of skin and the pulp of the grain, which provide contact between the aculeus and the coffee seed (endocarp) during the ovipositional process. The mesocarp of coffee berries does not facilitate the larger egg masses or provide adequate shelter for many Tephritidae maggots. Anastrepha ludens females also adjusted clutch number and size according to host size [42].

Novoseltsev et al. [43] concluded that female fecundity during the maturity stage in medfly follows a constant rate of egg laying. This behaviour was not observed during Test 2, where we detected a strong reduction in the size of the egg masses after the first day of medfly oviposition in Fuyu persimmon. Harris et al. [44] determined the first peak of medfly oviposition to occur at approximately 8 days old, followed by a substantial decline at 10 days old. At the beginning of the experiment in Fuyu persimmon, medfly females were 8 days old. However, we observed an average of one-third the number of eggs oviposited by $C$. capitata per puncture on the second, third, and fourth days compared to that on first day in Fuyu persimmon. 


\section{CONCLUSION}

The results of this study showed that the polyphagous fruit flies $A$. fraterculus and $C$. capitata presented differences in terms of the sizes of the egg masses per oviposition event in the same fruit hosts. Fuyu persimmon and papaya showed the highest mean number of eggs per puncture for both fruit flies, in addition to carambolas for medfly. Guava, coffee berries, and Tahiti acid lime for $A$. fraterculus and, guava and sweet orange for $C$. capitata were considered to be intermediate hosts. Many egg masses observed for $C$. capitata showed high quantities of eggs, which we considered to contain more eggs than are typically produced in a single clutch. Tahiti acid lime demonstrated almost no medfly oviposition. The first day of medfly oviposition in Fuyu persimmon resulted in approximately three times more eggs per puncture than the second, third, and fourth days.

\section{DISCLAIMER}

The products used for this research are commonly and predominantly use products in our area of research and country. There is absolutely no conflict of interest between the authors and producers of the products because we do not intend to use these products as an avenue for any litigation but for the advancement of knowledge. Also, the research was not funded by the producing company rather it was funded by personal efforts of the authors.

\section{ACKNOWLEDGMENTS}

This work was performed with the partial support of the Coordenação de Pessoal de Nível Superior - Brazil (Capes) [Financing code 001].

\section{COMPETING INTERESTS}

Authors have declared that no competing interests exist.

\section{REFERENCES}

1. Bonebrake TC, Boggs CL, McNally JM, Ranganathan J, Ehrlich PR. Oviposition behavior and offspring performance in herbivorous insects: Consequences of climatic and habitat heterogeneity. Oikos. 2010;119:927-934.

2. Khaliq $\mathrm{A}$, Ahmad $\mathrm{MH}$, Ullah $\mathrm{R}$, Anas $\mathrm{M}$. Behavioral ecology of oviposition in insects
- A dumpy review. Sky J Agric Res. 2015;4(1):1-7.

3. Thompson JN. Evolutionary ecology of the relationship between oviposition preference and performance of offspring in phytophagous insects. Entomol. Exp. Appl. 1988;57:3-14

4. Diaz-Fleischer F, Papaj DR, Prokopy RJ, Norrbom AL, Aluja M. Evolution of fruit fly oviposition behavior. Fruit flies (Diptera: Tephritidae): Phylogeny and evolution of behavior. Boca Raton, Florida, CRC Press. 2000;811-841.

5. Aluja M, Dıaz-Fleischer F, Papaj DR, Lagunes G, Sivinski J. Effects of age, diet, female density, and the host resource on egg load in Anastrepha ludens and Anastrepha obliqua (Diptera: Tephritidae). J Insect Physiol. 2001;47:975-988.

6. Follett PA. Puncture resistance in "Sharwil" avocado to oriental fruit fly and mediterranean fruit fly (Diptera: Tephritidae) oviposition. J Econ Entomol. 2009;102(3):921-926.

7. Dukas R, Prokopy RJ, Papaj DR, Duan JJ. Egg laying behavior of Mediterranean fruit flies (Diptera: Tephritidae): Is social facilitation important? Fla Entomol. 2001;84:665-671.

8. Prokopy RJ, Reynolds AH. Ovipositional enhancement through socially facilitated behaviour in Rhagoletis pomonella flies. Entomol. Exp. Appl. 1998;86:281-286.

9. Straw NA Evidence for an ovipositiondeterring pheromone in Tephritis bardanae (Schrank) (Diptera: Tephritidae). Oecologia. 1989;78:121-130.

10. Joachim-Bravo IS, Fernandes OA, De Bortoli SA, Zucoloto FS. Oviposition behavior of Ceratitis capitata Wiedemann (Diptera: Tephritidae): Association between oviposition preference and larval performance in individual females. Neotrop Entomol. 2001;30(4):559-564.

11. Burrack HJ, Zalom FG. Olive fruit fly (Diptera: Tephritidae) ovipositional preference and larval performance in several commercially important olive varieties in California. J Econ Entomol. 2008;101(3):750-758.

12. Papaj DR, Averill AL, Prokopy RJ, Wong TTY. Host-marking pheromone and use of previously established oviposition sites by the Mediterranean fruit fly (Diptera: Tephritidae). J Insect Behav. 1992;5:583598. 
13. Raga A, Souza-Filho MF, Machado RA, Sato ME, Siloto RC. Host ranges and infestation indices of fruit flies (Tephritidae) and lance flies (Lonchaeidae) in São Paulo State, Brazil. Fla Entomol. 2011;94:787794.

14. Zucchi RA, Moraes RCB. Fruit flies in Brazil - Anastrepha species their host plants and parasitoids; 2008.

Accessed 17 September 2020.

Available:http://www.lea.esalq.usp.br/anast repha.

15. Zucchi RA, Moraes RCB. Fruit flies in Brazil - Hosts and parasitoids of the Mediterranean fruit fly; 2012.

Accessed 17 September 2020.

Available:http://www.lea.esalq.usp.br/cerati tis.

16. Raga A, Galdino LT, Silva SB, Baldo FB, Sato ME. Comparison of insecticide toxicity in adults of the fruit flies Anastrepha fraterculus (Wied.) and Anastrepha grandis (Macquart) (Tephritidae). J Exp Agric Int. 2018;25(2): 1-8.

17. Ferreira DF. Sisvar: A computer analysis system to fixed effects split plot type designs. Rev Bras Biom. 2019;37(4):529535.

18. McDonald PT, Mclnnis PO. Ceratitis capitata: Effect of host fruit size on the numbers of eggs per clutch. Entomol Exp Appl 1985;37:207-213.

19. Bateman MA. The ecology of fruit flies. Annu Rev Entomol. 1972;17:493518.

20. Núñez-Bueno L. La mosca del mediterráneo. Rev ICA. 1987;21(1):1-8.

21. Krainacker DA, Carey JR, Vargas RI. Effect of larval host on life history traits of the mediterranean fruit fly, Ceratitis capitata. Oecologia. 1987;73:583-590.

22. Bisognin $M$, Nava DE, Lisbôa $H$, Bisognin AZ, Garcia MS, Valgas RA, DiezRodriguez $\mathrm{Gl}$, Botton $\mathrm{M}$, Antunes LEC. Biologia da mosca-das-frutas-sulamericana em frutos de mirtilo, amoreirapreta, araçazeiro e pitangueira. Pesqui Agropecu Bras. 2013;48:141-147.

23. Vargas RI, Nishida T. Life history and demographic parameters of Dacus latifrons (Diptera: Tephritidae). J Econ Entomol. 1985;78(6), 1242-1244.

24. Aluja M, Piñero J, Jácome I, DíazFleischer $F, \quad$ Sivinski J. Behavior of flies of the genus Anastrepha. In: fruit flies (Tephritidae): phylogeny and evolution of behavior. DelRay Beach: CRC Press. 2000;375-408.

25. Yuval B, Hendrichs J. Behavior of flies in the Genus Ceratitis (Dacinae: Ceratitidinae). 2000;427-457. Aluja M, Norrbom AL. Fruit flies (Tephritidae): Phylogeny and evolution of behavior. Boca Raton: CRC Press LLC. 2000;944.

26. Aluja M, Birke A, Guillén L, Díaz-

Fleischer F, Nestel D. Coping with an unpredictable and stressful environment: the life history and metabolic response to variable food and host availability in a polyphagous tephritid fly. J Insect Physiol. 2011;57:1592-1601.

27. Prokopy RJ, Duan JJ. Socially facilitated egg laying behavior in Mediterranean fruit flies. Behav Ecol Sociobiol. 1998;42:117122.

28. Dolores OS, Layme JM, Huaynate, CC. Nonhost status of commercial sweet granadilla (Passiflora ligularis) in Peru to Ceratitis capitata (Diptera: Tephritidae) and Anastrepha fraterculus. J Econ Entomol. 2020;113(3):1158-1175.

29. Seo ST, Tang CS., Hawaiian fruit flies (Diptera: Tephritidae): Toxicity of benzyl isothiocyanate against eggs or first instar of three species. J. Econ. Entomol. 1982;75:1132-1135.

30. Podleckis EV, Vreysen MJB, Robinson AS, Hendrichs J. Systems approaches as phytosanitary measures: Techniques and case studies. Area-Wide control of insect pests. Dordrecht: Springer; 2007.

31. Dias N, Nava DE, Garcia M, Silva F, Valgas R. Oviposition of fruit flies (Diptera: Tephritidae) and its relation with the pericarp of citrus fruits. Braz $\mathrm{J}$ Biol. 2018;78(3):443-448.

32. Raga A, Galdino LT. Sintomatologia do ataque de moscas-das-frutas (Diptera: Tephritidae) em citros. São Paulo: Instituto Biológico, 2017;16. (Technical Document $\left.\mathrm{n}^{\circ} 33\right)$.

Accessed 16 October 2020.

ISSN 1983-134X.

Available:http://www.biologico.sp.gov.br/up loads/dt/089dc7da-722e-4123-ae878bfd9f1f519a.pdf

33. Spitler GH, Armstrong JW, Couey HM. Mediterranean fruit fly (Diptera: Tephritidae) host status of commercial lemon. J Econ Entomol. 1984;77(6):14411444.

34. loannou CS, Papadopoulos NT, Kouloussis NA, Tananaki $\mathrm{Cl}$, Katsoyannos 
BI. Essential oils of citrus fruit stimulate oviposition in the Mediterranean fruit fly Ceratitis capitata (Diptera: Tephritidae). Physiol Entomol. 2012;37:330-339.

35. Gould WP, Hallman G. Host status of mamey sapote to Caribbean fruit fly (Diptera: Tephritidae). Fla Entomol. 2001;84(3):370-375.

36. Liendo $M C$, Parreño $M A$, Pietrek $A G$, Bouvet JP, Milla FH, Vera MT, Cladera JL, Segura DF. Infestation of fruit by conspecific and heterospecific females deters oviposition in two Tephritidae fruit fly species. J Appl Entomol. 2020;144: 701-709.

37. Farooq M, Baig S, Honey SF, Bajwa BE, Fazlullah, IH Shah. Evaluation of host susceptibility, preference and offspring performance of Zeugodacus cucurbitae (Coquillett) (Diptera: Tephritidae) on different hosts. Int. J. Trop. Insect Sci. 2020;40:93-99.

38. Freese $G$, Zwölfer $H$. The problem of optimal clutch size in a tritrophic system: the oviposition strategy of the thistle gallfly Urophora cardui (Diptera, Tephritidae). Oecologia.1996;108:293-302.

39. Souza Filho MF, Raga A, Zucchi RA. Incidencia de Anastrepha obliqua (Mac.) y Ceratitis capitata (Wied.) en carambola (Averrhoa carambola L.) en el ocho localidades del Estado de São Paulo,
Brasil. An Soc Entomol Brasil. 2000;29:367 - 371.

40. Tessmer MA, Kluge RA, Appezzato-daGlória $B$. The accumulation of tannins during the development of 'Giombo' and Fuyu' persimmon fruits. Sci Hortic. 2014;172:292-299.

41. Oroño L, Aluja M, Ovruski S, Rull J, Interdonato $\mathrm{R}$, Prado FE, Hilal M. Dynamics of soluble sugars and secondary metabolites in fruit of Juglans australis attacked by Anastrepha fraterculus and Ceratitis capitata (Diptera: Tephritidae). Arth.-Plant Interact. 2019;13: 411-421.

42. Aluja M, Birke A, Díaz-Fleischer F, Rull J. Phenotypic plasticity in clutch size regulation among populations of a potential invasive fruit fly from environments that vary in host heterogeneity and isolation. Bull Entomol Res. 2019;109(2):169-177.

43. Novoseltsev VN, Carey JR, Novoseltseva JA, Papadopoulos NT, Blay S, Yashin Al. Systemic mechanisms of individual reproductive life history in female medflies. Mech. Ageing Dev. 2004;125:77-87.

44. Harris EJ, Carey JR, Krainacker DA, Lee CYL. Life history of Ceratitis capitata (Diptera: Tephritidae) reared from mock orange in Hawaii. Environ Entomol. 1991;20(4):1048-1052.

(c) 2020 Sousa et al.; This is an Open Access article distributed under the terms of the Creative Commons Attribution License (http://creativecommons.org/licenses/by/4.0), which permits unrestricted use, distribution, and reproduction in any medium, provided the original work is properly cited.

Peer-review history:

The peer review history for this paper can be accessed here: http://www.sdiarticle4.com/review-history/62598 